\section{Principles of human evolution}

\author{
Principles of Human Evolution, Second Edition \\ R Lewin and RA Foley \\ Blackwell Science Ltd, Oxford, UK; 2003. 555 pp. \\ $£ 29.99$, paperback. ISBN 0632047046.
}

Heredity (2005) 94, 271. doi:10.1038/sj.hdy.6800579

Reviewed by Y Xue

I was born in a tiny town in the remote northeast of China and one of the books that fascinated me in my childhood during the Cultural Revolution was called 'Labour creates Human Beings'. From then on, I tried to find more about where humans came from and whether I could make a monkey work hard and so become a man and do my work for me. Is this book the answer to my dreams?

'Principles of Human Evolution' is the second edition of a textbook by the science writer Roger Lewin and now includes the anthropologist Robert Foley as a coauthor. It is aimed at students and takes them through basic ideas about human evolution and its background before coming to the main sections on the hominin fossils and their interpretation, including archaeological evidence from later time periods. It takes a broad view, and the authors are to be commended for recognizing the need to provide sections on genetics. These are clearly a subsidiary part of the book and it may seem hard to give the book to a geneticist to review for a genetics journal, but genetics has already made important contributions and seems likely to play an increasingly important role in this area in the future. How useful will the book be for geneticists?

The style of the book is accessible and the appearance is attractive, with a figure on almost every page. It is upto-date, including discussion of the recently described early hominins Sahelanthropus tchadensis, Orrorin tugenensis and Ardipithecus ramidus dating from a time close to the split between the human and ape lineages, as well as the earliest candidate anatomically modern human fossil, Homo sapiens idaltu dated to 160000 years ago from Ethiopia. Presentation is even-handed, as illustrated, for example, by the discussion of the number of species within the genus Homo, which can vary with different interpretations from two for the 'lumpers' to nine for the 'splitters'. Which is right? You have to decide yourself. An attractive feature is a 'Beyond the Facts' box at the end of each chapter, which gives the authors a chance to explore speculative ideas, such as arguing that relative dates are sometimes more useful than absolute ones.

The sections on genetics, however, were less satisfactory. On my first glance through, my eye was caught by a reference to Matt Hammer of the University of Arizona. Matt Hurles and Mike Hammer are well-known geneticists in the field of $\mathrm{Y}$ chromosome studies, but who is Matt Hammer? Any book will contain typos, but misunderstandings of genetics are common and some are significant, such as the confusion between the coalescence time of a locus and the divergence time between a pair of populations or species, or the lack of appreciation of the consequences of differences in effective population size between loci such as mitochondrial DNA and autosomal genes. The number and frequency of errors in these sections reveals the authors' lack of familiarity with genetics, but perhaps the greatest defect is the absence of pointers to websites since the world-wide web now dominates communication in genetics.

The strength of the book is as a textbook for students and others who want an introduction to paleoanthoropology and it succeeds in providing this. If the third edition adds a geneticist as a coauthor, perhaps I can learn how to train a monkey to review it.

Y Xue

The Wellcome Trust Sanger Institute, Wellcome Trust Genome Campus, Hinxton, Cambridge CB10 1SA, UK E-mail: ylx@sanger.ac.uk 